\title{
Suppression of allergic and inflammatory responses by essential oils derived from herbal plants and citrus fruits
}

\author{
MAI MITOSHI ${ }^{1}$, ISOKO KURIYAMA ${ }^{1}$, HIROTO NAKAYAMA ${ }^{2}$, HIRONARI MIYAZATO ${ }^{2}$, \\ KEIICHIRO SUGIMOTO ${ }^{2}$, YUKO KOBAYASHI ${ }^{3}$, TOMOKO JIPPO ${ }^{3}$, KOUJI KURAMOCHI ${ }^{4}$, \\ HIROMI YOSHIDA $^{1}$ and YOSHIYUKI MIZUSHINA ${ }^{1,5}$
}

\author{
${ }^{1}$ Laboratory of Food and Nutritional Sciences, Faculty of Nutrition, Kobe Gakuin University, Kobe, \\ Hyogo 651-2180; ${ }^{2}$ Research and Development Center, Nagaoka Perfumery Co., Ltd., Ibaraki, Osaka 567-0005; \\ ${ }^{3}$ Department of Food and Nutrition, Faculty of Human Life Sciences, Senri Kinran University, Suita, Osaka 565-0873; \\ ${ }^{4}$ Graduate School of Life and Environmental Sciences, Kyoto Prefectural University, Sakyo-ku, Kyoto 606-8522; \\ ${ }^{5}$ Cooperative Research Center of Life Sciences, Kobe Gakuin University, Kobe, Hyogo 650-8586, Japan
}

Received October 21, 2013; Accepted February 7, 2014

DOI: $10.3892 /$ ijmm.2014.1720

\begin{abstract}
The aim of the present study was to investigate the biological activity of 20 essential oils (EOs) derived from herbal plants and citrus fruits. The in vitro anti-allergic and antiinflammatory activities of these oils were investigated, and the EO which was found to have the strongest activity of the 20 EOs examined, was investigated further to identify its components and bioactive compounds. The in vitro anti-allergic activity was determined by measuring the release of $\beta$-hexosaminidase from rat basophilic leukemia (RBL-2H3) cells treated with the calcium ionophore, A23187. The in vitro anti-inflammatory activity was determined by measuring the production of tumor necrosis factor- $\alpha$ (TNF- $\alpha$ ) in RAW264.7 murine macrophages treated with lipopolysaccharide. Among the EOs examined, lemongrass [Cymbopogon citratus (DC.) Stapf] elicited the strongest anti-allergic and anti-inflammatory effects. A principal component of this EO is citral (3,7-dimethyl-2,6-octadien-1-al) (74.5\%), a mixture of the stereoisomers, geranial (trans-citral, $40.16 \%$ ) and neral (cis-citral, 34.24\%), as determined by chromatography-mass spectrometry analysis. The activities
\end{abstract}

Correspondence to: Dr Yoshiyuki Mizushina, Laboratory of Food and Nutritional Sciences, Faculty of Nutrition, Kobe Gakuin University, Nishi-ku, Kobe, Hyogo 651-2180, Japan

E-mail: mizushin@nutr.kobegakuin.ac.jp

Abbreviations: EOs, essential oils; TNF- $\alpha$, tumor necrosis factor- $\alpha$; TPA, 12- $O$-tetradecanoylphorbol-13-acetate; IgE, immunoglobulin E; LPS, lipopolysaccharide; GC, gas chromatography; MS, mass spec-

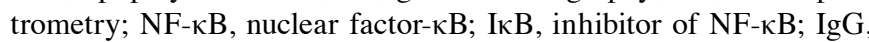
immunoglobulin G; FBS, fetal bovine serum; ELISA, enzyme-linked immunosorbent assay; SDS, sodium dodecyl sulfate; PCA, passive cutaneous anaphylaxis; DNP, dinitrophenyl; SD, standard deviation; $\mathrm{PKC}$, protein kinase $\mathrm{C}$

Key words: essential oil, lemongrass, citral, geranial, anti-allergic activity, anti-inflammatory activity of citral and geranial are similar to those of lemongrass EO. These compounds elicited significant in vivo anti-allergic and anti-inflammatory effects, suppressing an immunoglobulin $\mathrm{E}$ (IgE)-induced passive cutaneous anaphylactic reaction in mice and a 12-O-tetradecanoylphorbol-13-acetate-induced inflammatory mouse ear edema, respectively. Our data demonstrate that lemongrass EO and its constituents, citral and geranial, may be a therapeutic candidate for allergic and inflammatory diseases.

\section{Introduction}

Essential oils (EOs) are natural volatile complex compounds that are characterized by a strong scent and produced by aromatic plants as secondary metabolites (1). EOs have largely been employed for their well-known natural antitumor, antiinflammatory, antioxidant and anti-bacterial properties (2). Currently, approximately 3,000 EOs have been identified, 300 of which are commercially important, particularly in the pharmaceutical, agronomic, food, sanitary, cosmetic and perfume industries. EOs and some of their components are used in the perfume and cosmetic industry, as well as in the manufacture of sanitary products, dentistry and agriculture; they have also been employed as food preservatives, additives and natural remedies $(3,4)$. EOs are also used in massages as mixtures with vegetable oil, or in baths. Their most frequent use is in aromatherapy (1). Some EOs may have particular medicinal properties that are thought to cure certain organ dysfunctions or systemic disorders. EOs have long been used as the components of fragrances. Over past few years, there is a renewed interest in understanding their biological properties due to their potential novel applications in human health, agriculture and the environment.

The prevalence of allergic diseases, such as allergic rhinitis, atopic dermatitis, asthma and food allergies has increased in the majority of countries (5). Immunologically active mast cells and basophils express the high-affinity receptor for immunoglobulin $\mathrm{E}$ ( $\mathrm{IgE}$ ) on their surface and play critical roles in various 
biological processes associated with allergic diseases (6). The interaction of multivalent antigens with surface-bound $\operatorname{IgE}$ triggers the secretion of the mediators stored in cytoplasmic granules and causes a de novo synthesis of cytokines (7), that in turn activate the migration of neutrophils and macrophages, causing tissue inflammation (8).

Inflammation is an initial host immune reaction mediated by inflammatory cytokines, such as tumor necrosis factor- $\alpha$ (TNF- $\alpha$ ) (9). Macrophages play an important role in the host defense against noxious substances (10). Macrophage activation by lipopolysaccharide (LPS), a major component of Gramnegative bacteria outer membranes, leads to the increased production of pro-inflammatory cytokines, thereby mediating the major cytotoxic and pro-apoptotic mechanisms that participate in the innate response in many mammals (11). However, the cytokine overproduction by activated macrophages has been implicated in the pathophysiology of several inflammatory diseases, including rheumatoid arthritis, atherosclerosis, chronic hepatitis, pulmonary fibrosis and inflammatory brain diseases (11). Therefore, LPS-stimulated macrophages serve as a useful model for studying inflammation and the potential mechanisms of action of anti-inflammatory compounds.

In this study, the anti-allergic and anti-inflammatory properties of 20 different types of EOs isolated from herbal plants and citrus fruits were examined. Lemongrass EO exhibited the strongest anti-allergic and anti-inflammatory properties and therefore, the major chemical constituents of this EO were evaluated by gas chromatography (GC)-mass spectrometry (MS). These results are of great significance in recognizing the novel future applications of EOs derived from these plants.

\section{Materials and methods}

Materials. The 20 commercially available EOs were donated by Nagaoka Perfumery Co., Ltd. (Osaka, Japan). The 17 types of hydrodistilled EOs used in the study were from herbal plants, including basil (Ocimum basilicum L., produced in the Union of the Comoros), caraway (Carum carvi L., Europe), carrot seed (Daucus carota L., France), celery seed (Apium graveolens L., India), chamomile (Matricaria chamomilla L., Egypt), citronella (Cymbopogon winterianus Jowitt, Indonesia), clary sage (Salvia sclarea L., USA), clove (Syzygium aromaticum L., Madagascar), cumin (Cuminum cyminum L., India), eucalyptus (Eucalyptus globulus L., China), lemongrass [Cymbopogon citratus (DC.) Stapf, India], marjoram (Majorana hortensis Moench., France), nutmeg (Myristica fragrans Houtt., Indonesia), sage (Salvia officinalis L., Albania), sandalwood (Santalum album L., India), spearmint (Mentha spicata L., USA), and thyme (Thymus vulgaris L., India). The cold-pressed EOs were derived from 3 species of citrus fruits: lemon (Citrus limon L., USA), lime (C. aurantifolia Swingle, Mexico) and orange (C. sinensis L., Portugal). Five terpenoids, citral (3,7-dimethyl-2,6-octadien-1-al), geraniol, geranyl acetate, linalool and camphene were purchased from Sigma-Aldrich, Inc. (St. Louis, MO, USA). Tranilast and glycyrrhetinic acid, anti-allergic and antiinflammatory controls, respectively, were also obtained from Sigma-Aldrich, Inc. Geranial was prepared by the oxidation of geraniol with manganese dioxide, as previously described (12). For western blot analyses, anti-nuclear factor- $\kappa \mathrm{B}(\mathrm{NF}-\kappa \mathrm{B})$ p65 and anti-inhibitor of NF- $\kappa \mathrm{B}(\mathrm{I} \kappa \mathrm{B})-\alpha$ antibodies were purchased from Santa Cruz Biotechnology, Inc. (Santa Cruz, CA, USA). Horseradish peroxidase-conjugated anti-rabbit immunoglobulin $\mathrm{G}(\mathrm{IgG})$ antibody was obtained from Thermo Scientific (Kanagawa, Japan). All other reagents were of analytical grade and were obtained from Nacalai Tesque, Inc. (Kyoto, Japan).

Cells. RBL-2H3 rat basophilic leukemia and RAW264.7 murine macrophage cell lines were obtained from the American Type Culture Collection (ATCC; Manassas, VA, USA). The RBL-2H3 cells were cultured in Eagle's minimum essential medium supplemented with $4.5 \mathrm{~g}$ glucose/1 plus $10 \%$ fetal bovine serum (FBS), $5 \mathrm{mM}$ L-glutamine, $50 \mathrm{U} / \mathrm{ml}$ penicillin and $50 \mathrm{U} / \mathrm{ml}$ streptomycin. The RAW264.7 cells were cultured in Dulbecco's modified Eagle's medium supplemented with $4.5 \mathrm{~g}$ glucose/1 plus $10 \% \mathrm{FBS}, 5 \mathrm{mM}$ L-glutamine, $50 \mathrm{U} / \mathrm{ml}$ penicillin and $50 \mathrm{U} / \mathrm{ml}$ streptomycin. All cells were cultured at $37^{\circ} \mathrm{C}$ in their respective media in a humidified atmosphere of $5 \% \mathrm{CO}_{2} / 95 \%$ air.

Measurement of $\beta$-hexosaminidase release. Mast cell degranulation-mediated histamine release is accompanied by the release of $\beta$-hexosaminidase (13). Therefore, we performed a $\beta$-hexosaminidase release assay, as previously described (14) with slight modifications to determine the degranulation of mast cells as a measure of the anti-allergenic activity of the examined compounds. Briefly, the RBL-2H3 cells at $8 \times 10^{4}$ cells/well in 24-well plates were washed with Tyrode's buffer $\left(137 \mathrm{mM} \mathrm{NaCl}, 5.6 \mathrm{mM}\right.$ glucose, $11.9 \mathrm{mM} \mathrm{NaHCO}_{3}$, $2.7 \mathrm{mM} \mathrm{KCl}$ and $0.32 \mathrm{mM} \mathrm{NaH} \mathrm{PO}_{4}$ ) containing $1 \mathrm{mM}$ $\mathrm{CaCl}_{2}$ and $0.5 \mathrm{mM} \mathrm{MgCl}_{2}$, and the EOs (in 0.5\% DMSO) were then added to the culture wells at a final concentration of $100 \mu \mathrm{g} / \mathrm{ml}$. The cells were then stimulated with $5 \mu \mathrm{M}$ A23187 and incubated for $30 \mathrm{~min}$. The cell supernatant and total cell lysate dissolved in 2\% Triton X-100 were collected and mixed with substrate solution ( $2 \mathrm{mM} p$-nitrophenyl- $N$-acetyl- $\beta$-Dglucosaminide in $0.1 \mathrm{M}$ sodium citrate buffer, $\mathrm{pH} 4.5)$. The mixture was incubated for $90 \mathrm{~min}$ at $37^{\circ} \mathrm{C}$ and the reaction was then terminated by the addition of a stopping buffer containing a $0.2 \mathrm{M}$ glycine buffer at $\mathrm{pH} 11.0$. Absorbance at $405 \mathrm{~nm}$ was measured using a microplate reader (Vmax-K; Molecular Devices, LLC, Sunnyvale, CA, USA). The EO-mediated inhibition of $\beta$-hexosaminidase release and activity was expressed as the percentage inhibition and calculated using the following formula: $\%$ activity $=[(\beta$-hexosaminidase release in the absence of EO - $\beta$-hexosaminidase release in the presence of $\mathrm{EO}) / \beta$-hexosaminidase release in the absence of EO] x100.

Measurement of the EO-mediated inhibition of TNF- $\alpha$. The RAW264.7 cells were placed in a 12 -well plate at $5 \times 10^{4}$ cells/well and incubated for $24 \mathrm{~h}$. The cells were then pre-treated with each EO at a final concentration of $100 \mu \mathrm{g} / \mathrm{ml}$ in $0.5 \%$ DMSO for $30 \mathrm{~min}$ prior to the addition of LPS $(100 \mathrm{ng} / \mathrm{ml})$. Following LPS stimulation for $24 \mathrm{~h}$, the cell culture medium was collected to quantify the secreted TNF- $\alpha$ using a commercially available enzyme-linked immunosorbent assay (ELISA) development system (Bay Bioscience Co., Ltd., Kobe, Japan), in accordance with the manufacturer's instructions. The EO-mediated inhibition of TNF- $\alpha$ production was expressed as the percentage inhibition, calculated using the following formula: $\%$ activity $=[(\mathrm{TNF}-\alpha$ production in the absence of EO $-\mathrm{TNF}-\alpha$ 
production in the presence of EO)/TNF- $\alpha$ production in the absence of EO] x100.

$G C-M S$. GC-MS was performed using an Agilent 6890 gas chromatograph coupled with an Agilent 5972A MSD mass spectrometer (Agilent Technologies Japan, Ltd., Tokyo, Japan). The chromatograph was fitted with an InertCap WAX (polyethylene glycol)-fused silica capillary column (60 m x $0.25 \mathrm{~mm}$ i.d.; film thickness, $0.25 \mu \mathrm{m}$; GL Sciences, Inc., Tokyo, Japan), with purified helium ( $\geq 99.99995 \%$ ) carrier gas at $149 \mathrm{kPa}$ inlet pressure, in split/splitless mode and at $1.2 \mathrm{ml} / \mathrm{min}$. The oven temperature was programmed as follows: $5 \mathrm{~min}$ at $70^{\circ} \mathrm{C}$ and then $3^{\circ} \mathrm{C}$ increments $/ \mathrm{min}$ to $240^{\circ} \mathrm{C}$, with both the injector and transfer line held at $240^{\circ} \mathrm{C}$. The mass spectrometer operated at a $70 \mathrm{eV}$ electron impact, with an ion source temperature of $150^{\circ} \mathrm{C}$, and the data collected in full scan mode over a mass scan range revealed an $m / z$ of $27-400$. Each $0.6 \mu 1$ sample was injected in a split ratio of 1:60. A qualitative analysis was performed by similarity searches of private and commercial mass spectral databases (Wiley 275 and the National Institute of Standards and Technology 02).

Cell treatment and preparation of nuclear and whole cellular lysates and western blot analysis. The RAW264.7 cells were pre-treated with $10 \mu \mathrm{g} / \mathrm{ml}$ of a test compound for $30 \mathrm{~min}$ followed by treatment with $100 \mathrm{ng} / \mathrm{ml}$ LPS. After $30 \mathrm{~min}$, the nuclear proteins and whole cell lysates were collected, using the methods described in the study by Nishiumi et al (15). The protein concentrations of the nuclear proteins and whole cell lysates were measured using the $\mathrm{BCA}^{\mathrm{TM}}$ Protein Assay kit (Pierce, Rockford, IL, USA), according to the manufacturers instructions. Briefly, $25 \mu \mathrm{l}$ of each sample or $2 \mathrm{mg} / \mathrm{ml}$ BSA solution (as a standard) were added to a 96-well microplate well, and then $200 \mu \mathrm{l}$ of BCA Working Reagent were added to each well. The microplate was incubated at $37^{\circ} \mathrm{C}$ for $30 \mathrm{~min}$, and the protein concentration was determined by measuring the absorbance at $575 \mathrm{~nm}$. The nuclear proteins and whole cell lysates were subjected to western blot analysis to evaluate the nuclear translocation of NF- $\kappa \mathrm{B}$ and the protein expression of I $\mathrm{B}-\alpha$.

The nuclear proteins (30-50 $\mu \mathrm{g}$ of protein/sample) and whole cell lysates (50 $\mu \mathrm{g}$ of protein/sample) were boiled in a quarter volume of sample buffer [1 M Tris- $\mathrm{HCl}, \mathrm{pH} 7.5,640 \mathrm{mM}$ 2-mercaptoethanol, $0.2 \%$ bromphenol blue, $4 \%$ sodium dodecyl sulfate (SDS) and 20\% glycerol] and then separated on $10 \%$ SDS-polyacrylamide gels. The proteins in the gels were transferred onto a PVDF membrane. The membrane was blocked with $1 \%$ skimmed milk (for $\mathrm{NF}-\kappa \mathrm{B}$ ) or $5 \%$ bovine serum albumin in TBS-T (10 mM Tris- $\mathrm{HCl}, 100 \mathrm{mM} \mathrm{NaCl}$ and $0.5 \%$ Tween-20) (for I $\mathrm{B}-\alpha$ ) and probed with an anti-NF- $\kappa \mathrm{B}$ p65 $(1: 1,000)$ or anti-IкB- $\alpha(1: 1,000)$ antibody and subsequently with the horseradish peroxidase-conjugated secondary antibody. The protein-antibody complex was detected using ChemiLumi-ONE (Nacalai Tesque, Inc.) and an Image Reader (ImageQuant Imager 350/350Lumi; GE Healthcare Life Sciences, Uppsala, Sweden). The intensity of each band was analyzed using ImageJ software, which was developed at the National Institutes of Health. The results were expressed as a percentage of the mean protein expression ratio of the test compound-treated samples compared with that of the control group (i.e., the cells incubated in the absence of the test compound).
Animals. Female 6-week-old imprinting control region (ICR) mice (25-27 g body weight) were obtained from Japan SLC, Inc. (Hamamatsu, Japan), maintained on a standard moderate fat (MF) diet (Oriental Yeast Co., Ltd., Osaka, Japan), and provided with water ad libitum. All animal experiments were approved by the Kobe Gakuin University Animal Committee (Kobe, Japan) according to the university guidelines for the care and use of laboratory animals.

Measurement of anti-anaphylactic effects. The passive cutaneous anaphylaxis (PCA) reaction was measured according to a previous study (14). Mice were sensitized by an intradermal injection of $0.1 \mu \mathrm{g}$ of anti-dinitrophenyl (DNP)-IgE in the ear and intravenously challenged $4 \mathrm{~h}$ later with $0.2 \mathrm{ml}(1 \mathrm{mg} / \mathrm{ml})$ of a DNP-labeled human serum albumin solution containing $2 \%$ Evans blue dye. In a series of experiments, a test compound (100 $\mathrm{mg} / \mathrm{kg}$ ) was administered orally $2 \mathrm{~h}$ prior to antigen challenge. The animals in the control group received saline. The mice were subsequently sacrificed and the ears removed and weighed $30 \mathrm{~min}$ after the challenge. After dissolution of the ears in $200 \mu \mathrm{l}$ of $1 \mathrm{~N}$ potassium hydroxide $(\mathrm{KOH})$, they were incubated overnight at $37^{\circ} \mathrm{C}$ for the measurement of the amount of Evans blue dye present in the exudates. For this purpose, the dissolved tissue solution was added to $400 \mu \mathrm{l}$ of a mixture of acetone and $0.6 \mathrm{~N}$ phosphoric acid $(5 / 13, \mathrm{v} / \mathrm{v})$ and the optical density at $620 \mathrm{~nm}$ was measured. The amount of dye in the exudates was calculated from an Evans blue standard curve and the results expressed as a percentage of the mean exudate dye amount in the ear samples of the treated test mice compared with that of the controls.

Measurement of anti-inflammatory activity. The mouse inflammatory test was performed according to the method described in the study by Gschwendt et al (16). Briefly, an acetone solution containing a test compound at $500 \mu \mathrm{g} / 20 \mu \mathrm{l}$ or a vehicle control of $20 \mu \mathrm{l}$ of acetone was applied to the inner section of a mouse ear and, 30 min later, an acetone solution of 12- $O$-tetradecanoylphorbol-13-acetate (TPA, a chemical edema inducer) at $0.5 \mu \mathrm{g} / 20 \mu \mathrm{l}$ was applied to the same part of the ear; acetone, followed by a TPA application, served as a control. After $7 \mathrm{~h}$, a 6-mm diameter disk was obtained from the ear and weighed. The anti-inflammatory activity was determined by comparing the ear disk weight of the test group and the control group animals. The results were expressed as a percentage and were derived using the following formula: percentage activity $=[($ TPA only $)-($ tested compound plus TPA $)] /[($ TPA only $)-$ (vehicle)] x100.

Statistical analysis. All the results are expressed as the means \pm standard deviation (SD) of at least 3 independent determinations for each experiment. Statistical significance between each experimental group was analyzed using the Student's t-test, and a probability value of 0.01 and 0.05 was used as the criterion of significance.

\section{Results}

EO-induced inhibition of $\beta$-hexosaminidase release in mast cells. First, the inhibitory effects of 20 species of EOs on mast cell degranulation were investigated. $\beta$-hexosaminidase 

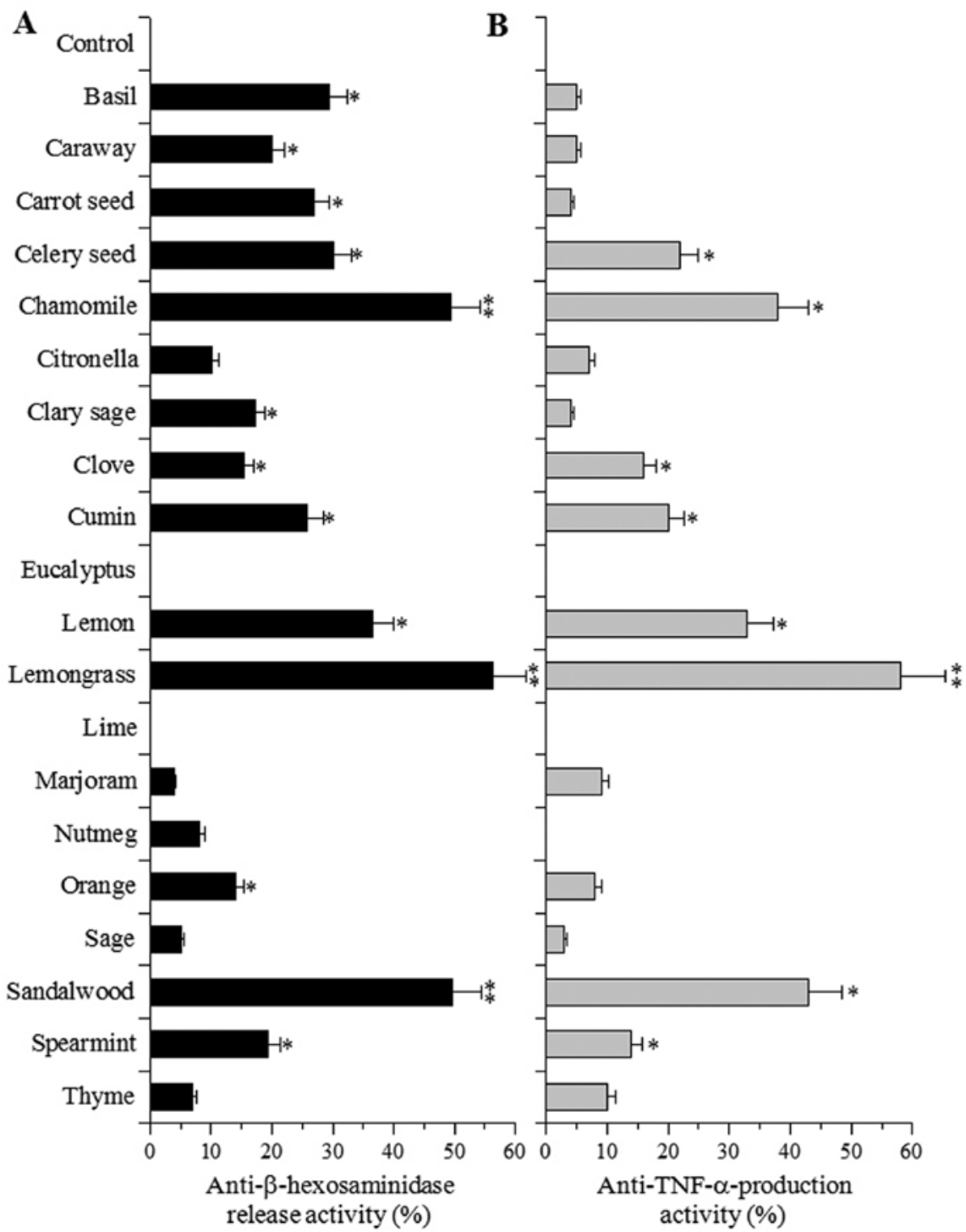

Figure 1. In vitro anti-allergic and anti-inflammatory activities of essential oils (EOs) isolated derived from 20 plant species. (A) Inhibition of $\beta$-hexosaminidase release in RBL-2H3 cells treated with the calcium ionophore, A23187. (B) Inhibition of tumor necrosis factor- $\alpha$ (TNF- $\alpha$ ) production by RAW264.7 cells treated with lipopolysaccharide (LPS). EOs, $100 \mu \mathrm{g} / \mathrm{ml}$; Data are shown as the means \pm standard deviation (SD) of 5 independent experiments. ${ }^{* *} \mathrm{P}<0.01$ and ${ }^{*} \mathrm{P}<0.05 \mathrm{vs}$. controls (untreated cells).

release is widely used as an indicator for evaluating the extent of degranulation by mast cells and the corresponding release of histamine and other chemical mediators, which is an important process in initiating the immediate type of hypersensitive reaction. The effects of the EOs (at $100 \mu \mathrm{g} / \mathrm{ml}$ ) on the release of a chemical mediator ( $\beta$-hexosaminidase) was investigated in the RBL-2H3 cells treated with the calcium ionophore, A23187. The EOs did not influence the growth of RBL-2H3 cells and did not inhibit $\beta$-hexosaminidase enzyme activity (data not shown). The degree of degranulation was calculated by assessing the $\beta$-hexosaminidase activity in the supernatant and cell lysate. Among the 20 EOs examined, treatment with EOs from chamomile, lemongrass and sandalwood produced $>40 \%$ inhibition of mast cell degranulation, as assessed by $\beta$-hexosaminidase release. Moreover, of the EOs examined, lemongrass EO showed the strongest inhibitory activity (Fig. 1A). On the other hand, EOs from eucalyptus and lime did not influence $\beta$-hexosaminidase release. A23187 is known to induce a calcium flux, which may further induce protein kinase $\mathrm{C}(\mathrm{PKC})$ activation, a process essential for mast cell degranulation (8). It is hence plausible that the $\beta$-hexosaminidase inhibition induced by treatment with EOs may affect PKC activity. The mechanisms through which EOs inhibit mast cell degranulation require further investigation.

EO-induced inhibition of TNF- $\alpha$ production in macrophages. We then investigated whether plant EOs, at $100 \mu \mathrm{g} / \mathrm{ml}$, inhibit the production of TNF- $\alpha$ induced by LPS stimulation in cultured cells. The inflammatory cytokine, TNF- $\alpha$, activates the $\mathrm{NF}-\kappa \mathrm{B}$ signaling pathway by binding to the TNF- $\alpha$ receptor, thereby initiating an inflammatory response implicated in various inflammatory diseases (17). In cultured RAW264.7 murine macrophage cells, none of the compounds examined showed cytotoxicity at $100 \mu \mathrm{g} / \mathrm{ml}$ (data not shown); the EOs 
Table I. Chemical composition of lemongrass essential oil (EO).
Components

Geranial [1] [2]

Composition (\%)

Neral [1]

Geraniol [3]

Geranyl acetate [4]

Linalool [5]

Methylheptenone

Camphene [6]

4-Nonanone

$\beta$-Caryophyllene

$\gamma$-Cadinene

Limonene

$\alpha$-Pinene

Tricyclene

Acetone

4-Heptanone

Others
40.16

34.24

5.11

2.89

1.45

1.44

1.39

1.38

1.09

0.96

0.33

0.28

0.18

0.13

0.06

8.91 had no effect on the proliferation of peritoneal macrophages. The RAW264.7 cells produced $693 \mathrm{pg} / \mathrm{ml}$ of TNF- $\alpha$ following stimulation with LPS. The rate of TNF- $\alpha$ production in the controls was set at $0 \%$. Among the EOs examined, those derived from lemongrass showed the strongest effect on TNF- $\alpha$ production ( $>50 \%$ inhibition) and those from chamomile, lemon and sandalwood displayed the second strongest effects (30-50\% inhibition) (Fig. 1B). EOs derived from eucalyptus, lime and nutmeg failed to affect TNF- $\alpha$ production ( $0 \%$ inhibition).

Association between the EO-induced inhibition of $\beta$-hexosaminidase release by mast cells and $T N F-\alpha$ production by macrophages. The possible association between the observed inhibition of $\beta$-hexosaminidase in mast cells and TNF- $\alpha$ inhibition in macrophages was confirmed by comparing the effects of the 20 EOs on these biological activities. The inhibition of $\beta$-hexosaminidase release showed a high correlation with TNF- $\alpha$ inhibition, with a significant correlation coefficient $\left(\mathrm{R}^{2}=0.783\right)$. These results led us to speculate that the anti-allergic activity related to the inhibition of $\beta$-hexosaminidase release and the anti-inflammatory effects induced by the suppression of TNF- $\alpha$ may be EO-related events within a shared biological pathway.

Among the 20 EOs examined, lemongrass EO produced the strongest inhibitory activities in the cultured cells (Fig. 1); thereafter we focused on lemongrass EO.

Identification of lemongrass EO components. The association between the biological activity of lemongrass EO and EO composition was clarified by an analysis of the primary EO components by GC-MS. In total, 138 compounds were detected in the EO, of which 40 components were identified, and the 15 major compounds are listed in Table I. The 2 main compounds representing $>30 \%$ of the total content were geranial and neral (40.16 and $34.24 \%$, respectively). A mixture of these stereoisomic monoterpene aldehydes is referred to as

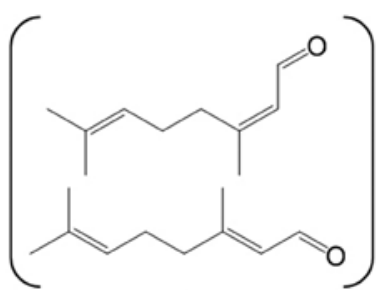

1

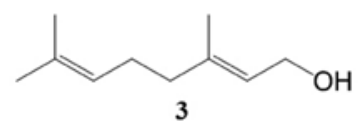

3
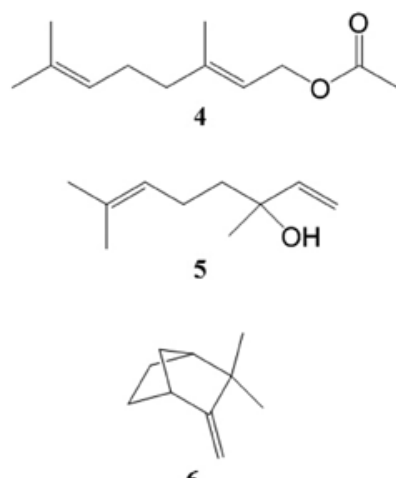

6

Figure 2. Structure of the major components of lemongrass essential oil (EO): Citral [(3,7-dimethyl-2,6-octadien-1-al), a mixture of stereoisomers, geranial (trans-isomer) and neral (cis-isomer)] [1], geranial [2], geraniol [3], geranyl acetate [4], linalool [5] and camphene [6].

citral. Of the identified components, 5 compounds, citral [1], geraniol [3], geranyl acetate [4], linalool [5] and camphene [6], were commercially available. Geranial [2] was chemically synthesized. Preparations of compounds 1-6 contain terpenoids of low molecular weight, and their corresponding chemical structures are shown in Fig. 2.

Effects of major lemongrass EO components on $\beta$-hexosaminidase release and TNF- $\alpha$ production in cultured cells. Based on the above results, the inhibitory effects of $100 \mu \mathrm{g} / \mathrm{ml}$ of lemongrass EO and its major components, compounds 1-6, on $\beta$-hexosaminidase release by mast cells and TNF- $\alpha$ production by macrophages were investigated. In the RBL-2H3 and RAW264.7 cells, these compounds did not show cytotoxicity at $100 \mu \mathrm{g} / \mathrm{ml}$ (data not shown).

Citral [1] (a mixture of neral and geranial) and geranial [2], which is a trans-isomer of citral, markedly inhibited the release of $\beta$-hexosaminidase induced by the calcium ionophore, A23187, and this inhibitory effect was similar to that elicited by lemongrass EO (Fig. 3A). On the other hand, 4 other components, geraniol [3], geranyl acetate [4], linalool [5] and camphene [6], exerted weak or moderate effects, and the inhibitory effect on the release of $\beta$-hexosaminidase elicited by compounds 3-6 was 2-fold weaker than that elicited by compounds 1-2 or lemongrass EO.

The effects of compounds 1-6 on TNF- $\alpha$ production were similar to those on $\beta$-hexosaminidase release, and compounds 1-2 and lemongrass EO exerted stronger inhibitory effects than compounds 3-6 (Fig. 3B). These results 


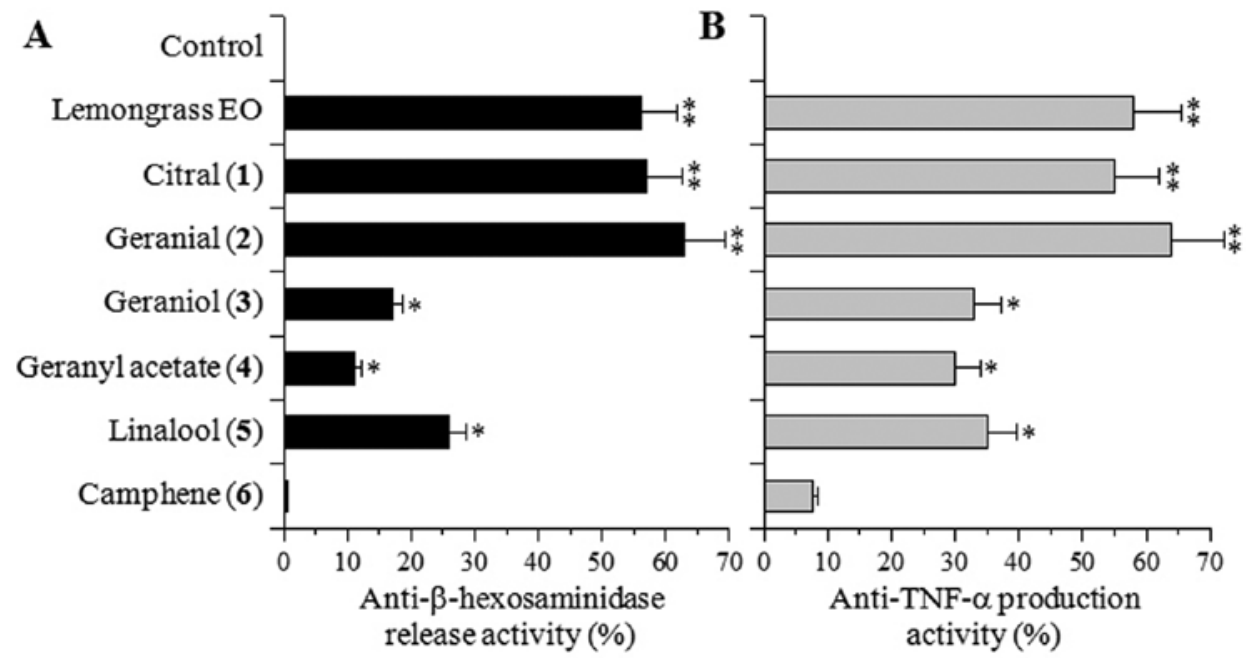

Figure 3. In vitro anti-allergic and anti-inflammatory activities of the major components of lemongrass essential oil (EO) (compounds 1-6). (A) Inhibition of $\beta$-hexosaminidase release by RBL-2H3 cells treated with the calcium ionophore, A23187. (B) Inhibition of tumor necrosis factor- $\alpha$ (TNF- $\alpha$ ) production by RAW264.7 cells treated with lipopolysaccharide (LPS). Compounds, $100 \mu \mathrm{g} / \mathrm{ml}$. Data are shown as the means \pm standard deviation (SD) of 5 independent experiments. ${ }^{* *} \mathrm{P}<0.01$ and ${ }^{*} \mathrm{P}<0.05$ vs. controls (untreated cells).

$\mathbf{A}$

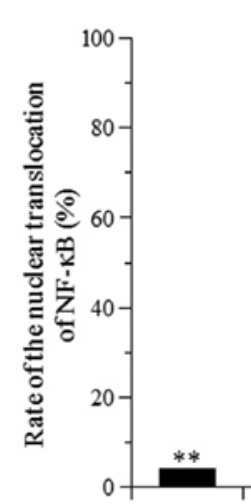

Lemongrass EO

Citral (1)

Geranial(2)

LPS

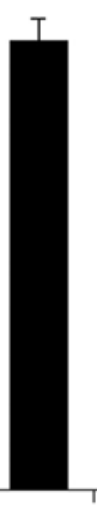

$-$

-
-
-

$-$

$+$

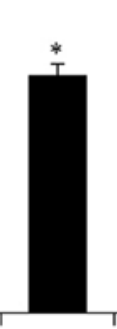

+
-

$-$

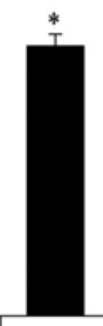

$-$

$+$

$+$

-

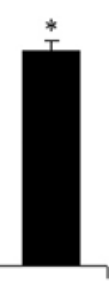

$-$

$-$

$+$
B

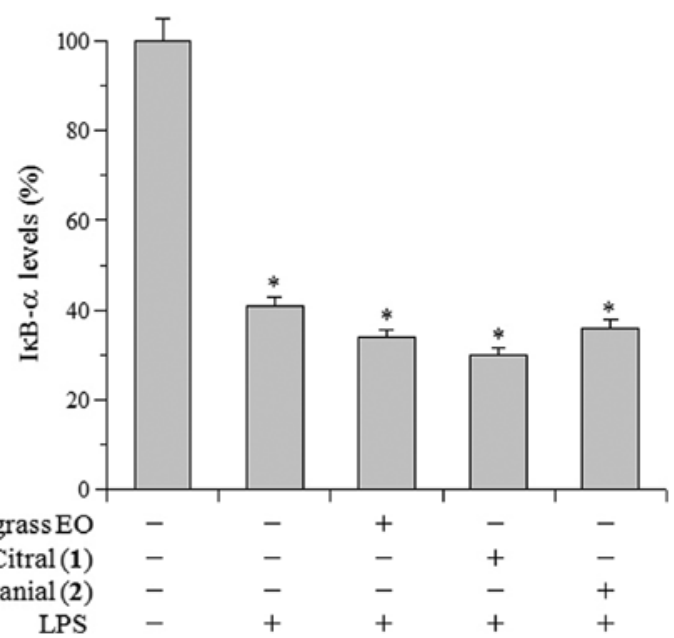

Figure 4. The inhibitory activities of lemongrass essential oil (EO) and its major components, citral [1] and geranial [2], against inflammatory responses in cultured cells. RAW264.7 cells were pre-treated with $10 \mu \mathrm{g} / \mathrm{ml}$ lemongrass EO, citral [1] or geranial [2], followed by incubation with lipopolysaccharide (LPS) for $30 \mathrm{~min}$. (A) The nuclear translocation of nuclear factor- $\kappa \mathrm{B}(\mathrm{NF}-\kappa \mathrm{B})$ and (B) the protein expression of inhibitor of NF- $\kappa \mathrm{B}(\mathrm{I} \kappa \mathrm{B})$ - $\alpha$ were evaluated by western blot analysis as described in Materials and methods. (A) The protein expression of NF- $\kappa \mathrm{B}$ in the RAW264.7 cells treated with LPS in the absence of the test compound was taken as $100 \%$. (B) The I $\kappa \mathrm{B}-\alpha$ protein amount in the RAW264.7 cells not stimulated with LPS in the absence of the test compound was taken as $100 \%$. Data are shown as the means \pm standard deviation (SD) of 3 independent experiments. ${ }^{* *} \mathrm{P}<0.01$ and ${ }^{*} \mathrm{P}<0.05$ vs. controls (untreated cells).

suggest that citral [1] and/or geranial [2] are the bioactive components conferring the biological activities to lemongrass EO. Therefore, we sought to explore compounds 1-2 further.

The inhibitory activity of citral [1] and geranial [2] against LPS-induced inflammatory responses in cultured macrophages. $\mathrm{NF}-\kappa \mathrm{B}$ activation is known to be the rate-controlling factor during an inflammatory response. Therefore, the inhibitory effects of lemongrass EO and its major components, citral [1] and geranial [2], on the LPS-induced nuclear translocation of NF- $\kappa \mathrm{B}$ were examined in RAW264.7 cells (Fig. 4A). Western blot analysis revealed that $10 \mu \mathrm{g} / \mathrm{ml}$ of citral [1] and geranial [2] inhibited the LPS-induced NF- $\kappa$ B nuclear translocation, with 40 and 52\% inhibition, respectively. Lemongrass
$\mathrm{EO}$, at $10 \mu \mathrm{g} / \mathrm{ml}$, also inhibited the nuclear translocation of $N F-\kappa B$, and this inhibitory activity was similar to that of compounds $1-2$.

Stimulation with LPS results in the activation of Toll-like receptor 4 and that of downstream I $\mathrm{B}$ kinases (IKKs), which in turn phosphorylate $\mathrm{I} \kappa \mathrm{B}$, resulting in $\mathrm{I} \kappa \mathrm{B}$ degradation and the translocation of $\mathrm{NF}-\kappa \mathrm{B}$ into the nucleus (18). I $\kappa \mathrm{B}-\alpha$ inhibits $\mathrm{NF}-\kappa \mathrm{B}$ by masking the nuclear localization signals (NLS) of $\mathrm{NF}-\kappa \mathrm{B}$ proteins and maintaining them in a sequestered and inactive state in the cytoplasm (19). In addition, IкB- $\alpha$ blocks the ability of the NF- $\kappa \mathrm{B}$ transcription factor to bind to DNA, which is required for the proper functioning of NF- $\mathrm{B}$ (20). Therefore, the effects of lemongrass EO and compounds 1-2 on the LPS-induced decrease in the protein expression of IкB- $\alpha$ 

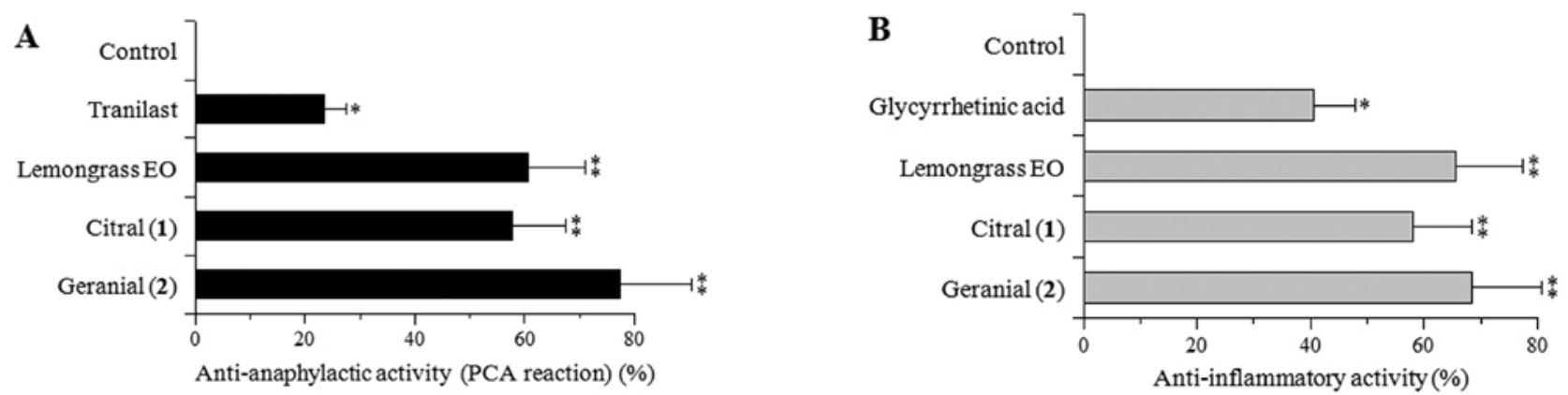

Figure 5. In vivo anti-allergic and anti-inflammatory activities of lemongrass essential oil (EO) and its major components, citral [1] and geranial [2]. (A) Antiallergic activity of tranilast (the positive control), lemongrass EO, and compounds 1 and 2 on the passive cutaneous anaphylaxis (PCA) reaction. Each compound $(100 \mathrm{mg} / \mathrm{kg}$ each) was orally administrated to mice, and the immunoglobulin E (IgE)-dependent PCA reaction was investigated. (B) Anti-inflammatory activity of glycyrrhetinoic acid (positive control), lemongrass EO, and compounds 1 and 2 toward TPA-induced edema in a mouse model of ear edema. Each compound $(500 \mu \mathrm{g})$ was applied individually to one ear of a mouse, and after $30 \mathrm{~min}$, TPA was applied to both ears. Edema was evaluated after $7 \mathrm{~h}$. The inhibitory effects are expressed as the percentage of edema. Data are shown as the means \pm standard deviation (SD) of 6 independent experiments. ${ }^{* *} \mathrm{P}<0.01$ and ${ }^{*} \mathrm{P}<0.05$ vs. controls (animals treated with saline).

were examined in the RAW264.7 cells (Fig. 4B). IкB- $\alpha$ protein expression was reduced by $59 \%$ following LPS stimulation (Fig. 4B). The amount of I $\kappa \mathrm{B}-\alpha$ protein in the cells treated with compounds $1-2(10 \mu \mathrm{g} / \mathrm{ml}$ each $)$ was almost the same as that in the LPS-treated cells (the I $\kappa \mathrm{B}-\alpha$ protein level was approximately $35 \%$ compared to that in the control untreated cells), suggesting that compounds 1-2 did not influence the protein expression of I $\mathrm{B}-\alpha$. These results demonstrate that lemongrass EO and its major components suppress the $\mathrm{NF}-\kappa \mathrm{B}$ nuclear translocation through an $\mathrm{I} \kappa \mathrm{B}-\alpha$-independent mechanism. The effects of these compounds at other points in the $\mathrm{NF}-\kappa \mathrm{B}$ signaling pathway required further investigation.

In vivo anti-allergic and anti-inflammatory activities of citral [1] and geranial [2]. The IgE-mediated PCA reaction in vivo is a method used for studying the mechanisms of the immediate hypersensitivity reaction. As shown in Fig. 5A, $100 \mathrm{mg} / \mathrm{kg}$ of tranilast, a commonly used anti-allergic drug that targets mast cell degranulation and inhibits the PCA reaction, was used as a positive control. Lemongrass EO and its major components, citral [1] and geranial [2], at $100 \mathrm{mg} / \mathrm{kg}$ also inhibited the PCA reaction in the mice by $60.7,57.7$ and $77.4 \%$, respectively. The inhibitory effects of lemongrass EO and compounds 1-2 were $>2$-fold stronger than those of tranilast, suggesting a great potential for use as anti-allergic compounds.

We examined the anti-inflammatory activity of lemongrass EO, citral [1] and geranial [2] by examining their effects on TPA-induced inflammatory edema of the mouse ear in vivo. The application of TPA $(0.5 \mu \mathrm{g})$ to the mouse ears induced edema, resulting in a $241 \%$ increase in the weight of the ear disk $7 \mathrm{~h}$ after application. Pre-treatment with $500 \mu \mathrm{g} / \mathrm{ear}$ of these compounds significantly suppressed inflammation, and the strength of the inhibitory effect was ranked as follows: geranial [2] > lemongrass EO > citral [1] (Fig. 5B). Therefore, the in vivo anti-inflammatory effects of these compounds displayed the same order as their in vivo anti-allergic effects (Fig. 5A). These results suggest that the anti-allergic effects of the components of lemongrass EO positively correlate with the anti-inflammatory activity observed. Glycyrrhetinic acid (500 $\mu \mathrm{g} / \mathrm{ear})$, a known anti-inflammatory agent, had a $40.5 \%$ anti-inflammatory effect in this assay system, and these compounds were found to be approximately 1.5 -fold more effective than this agent.

The biological effects elicited by compounds 1-2 were similar to those produced by almost the same concentrations of lemongrass EO (Figs. 3-5), suggesting that the anti-allergy and anti-inflammatory effects of lemongrass EO are largely due to its 2 major components, citral [1] and/or geranial [2].

\section{Discussion}

Over the years, EOs have attracted much attention in scientific research and are increasingly used in pharmaceutical, nutritional and cosmetic industrial applications $(21,22)$, primarily due to their potent anti-microbial (23), antioxidant (24), anticancer (25) and anti-inflammatory activities (26) of EOs. The infection process induces inflammation, during which inflammatory mediators, such as cytokines are released from phagocytes (27). As various skin disorders, including atopic dermatitis (28) and acne vulgaris (29), are associated with infection-induced inflammation, the presence of anti-inflammatory agents may explain the effectiveness of certain plant-derived EOs in the treatment of these syndromes. In several regions worldwide, aromatic herbs play major roles in primary health care, particularly in rural areas (30). Thus, an understanding of herbal biological activities may further the effectiveness and the use of many of their functional components, particularly as beneficial additives in medical, nutritional and cosmetic products.

In the present study, 20 EOs were selected as known herbal plant- and citrus fruit-derived EOs. Among the plantderived EOs worldwide, the compounds selected represent the most well known and most commonly used materials in perfume preparations. These EOs were isolated by hydrodistillation or cold-pressing and were confirmed to be free of any contamination, such as heavy metals and pesticides by GC-MS analyses (data not shown). Among these 20 EOs, lemongrass EO exhibited the strongest inhibitory activity on mast cell degranulation, which was assessed by quantifying 
$\beta$-hexosaminidase release from RBL-2H3 cells treated with the calcium ionophore, A23187 (Fig. 1A) and the production of TNF- $\alpha$, a pleiotropic inflammatory cytokine, by RAW264.7 murine macrophages treated with LPS (Fig. 1B). We observed that individual constituents of lemongrass EO, including citral [1], which is a mixture of stereoisomers, geranial (transisomer) [2] and neral (cis-isomer), comprising $74.40 \%$ of lemongrass EO (Table I), inhibited NF- $\mathrm{BB}$ nuclear translocation by LPS, and suppressed TNF- $\alpha$ production in macrophage cell culture experiments in vitro (Figs. 3-5). These compounds also exhibited potent anti-allergic/anti-inflammatory activity in vivo. Lemongrass EO and its major components, such as citral [1] and geranial [2] exhibited anti-inflammatory activity in a TPA-induced mouse model of ear edema, although the underlying molecular mechanisms remain unelucidated (Fig. 5B). Since the activation of NF- $\mathrm{BB}$ has been observed in a model of TPA-induced ear edema (31), we hypothesized that the anti-inflammatory effects may be, at least in part, dependent on the inhibition of NF- $\kappa \mathrm{B}$ activation. At present, citral [1] and geranial [2] are regarded as promising anti-inflammatory agents. Our study indicates that these compounds are useful as $\mathrm{NF}-\kappa \mathrm{B}$ inhibitors and may be potent chemopreventive agents against inflammation. Among the lemongrass EO components, citral [1] and geranial [2] inhibited the release of $\beta$-hexosaminidase and the production of $\mathrm{TNF}-\alpha$, while geraniol [3] and geranyl acetate [4] did not have any effects (Fig. 3), suggesting that the ketone group of citral may be important for these observed inhibitory activities.

Lemongrass is native to India and tropical Asia. It is widely used as an herb in Asian cuisine. It has a subtle citrus flavor and can be dried and powdered, or used fresh. Lemongrass is commonly used in teas, soups and curries. It is also suitable for poultry, fish, beef and seafood. It is often used as a tea in African countries, such as Togo and the Democratic Republic of Congo, as well as in Latin American countries, such as Mexico. Among the components of lemongrass, geranial [2] has a strong lemon odor. The lemon odor of neral is less intense, but sweeter. Citral [1], on the other hand, is an aromatic compound used in perfumery for its citrus effect. Citral [1] is also used as a flavor and for fortifying lemon oil. This plant containing citral [1] is used in folk medicine as an anti-spasmodic, hypotensive, anti-convulsant, analgesic, antiemetic, antitussive, anti-rheumatic, antiseptic, anti-bacterial, anti-diarrheal and antioxidant agent, as well as in the treatment of nervous and gastrointestinal disorders and fevers (32). In this study, lemongrass EO was found to have anti-allergic and anti-inflammatory activities; however, the mechanisms behind these different bioactivities were not examined in detail. The association between the above-mentioned biological activities and the blocking of the nuclear translocation of NF- $\kappa \mathrm{B}$ and $\mathrm{TNF}-\alpha$ production requires further investigation.

Modern aromatherapy for allergic and inflammatory diseases has been developed primarily based on clinical trials of EOs by several pioneers; however, scientific research on the physiological role of these EOs against allergic and inflammatory responses is still at a primitive stage. The elucidation of the pharmacological functions of lemongrass EO in vivo may provide a rationale for the clinical application of this EO as an anti-allergic and anti-inflammatory substance. In conclusion, our data provide strong scientific evidence and highlight the benefits of lemongrass EO and its constituents, citral [1] and geranial [2], for use in medical and/or cosmetic applications.

\section{Acknowledgements}

This study was supported in part by the Ministry of Education, Culture, Sports, Science and Technology (MEXT, Japan)Supported Program for the Strategic Research Foundation at Private Universities, 2012-2016. Y.M. received Grants-in-Aid for Scientific Research (C) (no. 24580205) from MEXT and the Hyogo Science and Technology Association (Japan). I.K. received a Grant-in-Aid for Young Scientists (B) (no. 23710262) from MEXT.

\section{References}

1. Bakkali F, Averbeck S, Averbeck D and Idaomar M: Biological effects of essential oils-a review. Food Chem Toxicol 46: 446-475, 2008.

2. Woollard AC, Tatham KC and Barker S: The influence of essential oils on the processå of wound healing: a review of the current evidence. J Wound Care 16: 255-257, 2007.

3. Prabuseenivasan $S$, Jayakumar $M$ and Ignacimuthu S: In vitro antibacterial activity of some plant essential oils. BMC Complement Altern Med 6: 39, 2006.

4. Clarke JO and Mullin GE: A review of complementary and alternative approaches to immunomodulation. Nutr Clin Pract 23: 49-62, 2008

5. Wüthrich B: Epidemiology of the allergic diseases: are they really on the increase? Int Arch Allergy Appl Immunol 90 (Suppl 1): S3-S10, 1989.

6. Stevens RL and Austen KF: Recent advances in the cellular and molecular biology of mast cells. Immunol Today 10: 381-386, 1989.

7. Plaut M, Pierce JH, Watson CJ, Hanley-Hyde J, Nordan RP and Paul WE: Mast cell lines produce lymphokines in response to cross-linkage of $\mathrm{Fc}$ epsilon RI or to calcium ionophores. Nature 339: 64-67, 1989.

8. Gordon JR, Burd PR and Galli SJ: Mast cells as a source of multifunctional cytokines. Immunol Today 11: 458-464, 1990.

9. Ronis MJ, Butura A, Korourian S, Shankar K, Simpson P, Badeaux J, Albano E, Ingelman-Sundberg $M$ and Badger TM: Cytokine and chemokine expression associated with steatohepatitis and hepatocyte proliferation in rats fed ethanol via total enteral nutrition. Exp Biol Med (Maywood) 233: 344-355, 2008.

10. Pierce GF: Macrophages: important physiologic and pathologic sources of polypeptide growth factors. Am J Respir Cell Mol Biol 2: 233-234, 1990.

11. Boscá L, Zeini M, Través PG and Hortelano S: Nitric oxide and cell viability in inflammatory cells: a role for $\mathrm{NO}$ in macrophage function and fate. Toxicology 208: 249-258, 2005.

12. Hirano M, Yakabe S, Chikamori H, Clark JH and Morimoto T: Oxidation by chemical manganese dioxide. Part 3. Oxidation of benzylic and allylic alcohols, hydroxyarenes and aminoarenes. J Chem Res (S): 770-771, 1998.

13. Razin E, Mencia-Huerta JM, Stevens RL, Lewis RA, Liu FT, Corey E and Austen KF: IgE-mediated release of leukotriene C4, chondroitin sulfate E proteoglycan, beta-hexosaminidase, and histamine from cultured bone marrow-derived mouse mast cells. J Exp Med 157: 189-201, 1983.

14. Sato H, Kobayashi Y, Hattori A, Suzuki T, Shigekawa M and Jippo T: Inhibitory effects of water-soluble low-molecular-weight $\beta-(1,3-1,6)$ D-glucan isolated from Aureobasidium pullulans 1A1 strain black yeast on mast cell degranulation and passive cutaneous anaphylaxis. Biosci Biotechnol Biochem 76: 84-88, 2012.

15. Nishiumi S, Yamamoto N, Kodoi R, Fukuda I, Yoshida K and Ashida H: Antagonistic and agonistic effects of indigoids on the transformation of an aryl hydrocarbon receptor. Arch Biochem Biophys 470: 187-199, 2008.

16. Gschwendt M, Kittstein W, Fürstenberger G and Marks F: The mouse ear edema: a quantitatively evaluable assay for tumor promoting compounds and for inhibitors of tumor promotion. Cancer Lett 25: 177-185, 1984.

17. Aggarwal BB: Signalling pathways of the TNF superfamily: a double-edged sword. Nat Rev Immunol 3: 745-756, 2003. 
18. Hashimoto T, Nonaka Y, Minato K, Kawakami S, Mizuno M, Fukuda I, Kanazawa K and Ashida H: Suppressive effect of polysaccharides from the edible and medicinal mushrooms, Lentinus edodes and Agaricus blazei, on the expression of cytochrome P450s in mice. Biosci Biotechnol Biochem 66: 1610-1614, 2002.

19. Jacobs MD and Harrison SC: Structure of an IkappaBalpha/ NF-kappaB complex. Cell 95: 749-758, 1998.

20. Verma IM, Stevenson JK, Schwarz EM, Van Antwerp D and Miyamoto S: Rel/NF-kappa B/I kappa B family: intimate tales of association and dissociation. Genes Dev 9: 2723-2735, 1995.

21. Cheng SS, Lin HY and Chang ST: Chemical composition and antifungal activity of essential oils from different tissues of Japanese Cedar (Cryptomeria japonica). J Agric Food Chem 53 614-619, 2005.

22. Ksouri R, Falleh H, Megdiche W, Trabelsi N, Mhamdi B Chaieb K, Bakrouf A, Magné C and Abdelly C: Antioxidant and antimicrobial activities of the edible medicinal halophyte Tamarix gallica L. and related polyphenolic constituents. Food Chem Toxicol 47: 2083-2091, 2009.

23. Lo Cantore P, Shanmugaiah V and Iacobellis NS: Antibacterial activity of essential oil components and their potential use in seed disinfection. J Agric Food Chem 57: 9454-9461, 2009.

24. Dutra RC, Leite MN and Barbosa NR: Quantification of phenolic constituents and antioxidant activity of Pterodon emarginatus vogel seeds. Int J Mol Sci 9: 606-614, 2008.

25. Kumar A, Malik F, Bhushan S, Sethi VK, Shahi AK, Kaur J, Taneja SC, Qazi GN and Singh J: An essential oil and its major constituent isointermedeol induce apoptosis by increased expression of mitochondrial cytochrome $\mathrm{c}$ and apical death receptors in human leukaemia HL-60 cells. Chem Biol Interact 171: 332-347, 2008 .
26. Chao LK, Hua KF, Hsu HY, Cheng SS, Liu JY and Chang ST: Study on the antiinflammatory activity of essential oil from leaves of Cinnamomum osmophloeum. J Agric Food Chem 53: 7274-7278, 2005

27. Lourens AC, Reddy D, Başer KH, Viljoen AM and Van Vuuren SF: In vitro biological activity and essential oil composition of four indigenous South African Helichrysum species. J Ethnopharmacol 95: 253-258, 2004.

28. Tsukahara H, Shibata R, Ohshima Y, Todoroki Y, Sato S, Ohta N, Hiraoka M, Yoshida A, Nishima S and Mayumi M: Oxidative stress and altered antioxidant defenses in children with acute exacerbation of atopic dermatitis. Life Sci 72: 2509-2516, 2003.

29. Grange PA, Chéreau C, Raingeaud J, Nicco C, Weill B, Dupin N and Batteux F: Production of superoxide anions by keratinocytes initiates $P$. acnes-induced inflammation of the skin. PLoS Pathog 5: e1000527, 2009

30. Kamatou GP, Viljoen AM, Gono-Bwalya AB, van Zyl RL, van Vuuren SF, Lourens AC, Basser KH, Demirci B, Lindsey KL, van Staden J and Steenkamp P: The in vitro pharmacological activities and a chemical investigation of three South African Salvia species. J Ethnopharmacol 102: 382-390, 2005

31. Medeiros R, Otuki MF, Avellar MC and Calixto JB: Mechanisms underlying the inhibitory actions of the pentacyclic triterpene alpha-amyrin in the mouse skin inflammation induced by phorbol ester 12- $O$-tetradecanoylphorbol-13-acetate. Eur J Pharmacol 559: 227-235, 2007.

32. Shah G, Shri R, Panchal V, Sharma N, Singh B and Mann AS: Scientific basis for the therapeutic use of Cymbopogon citratus, stapf (Lemon grass). J Adv Pharm Technol Res 2: 3-8, 2011. 